\title{
EMILY DICKINSON E A POÉTICA DA BREVIDADE: DO HAICAI AO IMAGISMO
}

\section{José Lira*}

Resumo: Este trabalho esboça uma análise comparativa entre a poética da brevidade em Emily Dickinson (1830-1886), poeta norte-americana cuja obra póstuma só recentemente obteve pleno reconhecimento da crítica literária, e a antiga arte haicaística japonesa, por um lado, e, por outro, o imagismo anglo-americano do séc. XX. Limito-me a ressaltar, neste estudo, algumas semelhanças de estilo e conteúdo mais visíveis na obra de Emily Dickinson em relação a essas duas distantes épocas literárias que os críticos costumam correlacionar.

Palavras-chave: Literatura comparada; Emily Dickinson; haicai; imagismo.

Para ilustrar a distinção entre as noções de peso e leveza numa obra artística, Calvino (1990, p. 28), que se posiciona em favor desta última, apóia-se numa asserção de Valéry - il faut être léger comme l'oiseau, et non comme la plume - para afirmar que a leveza de um texto literário estaria "associada à precisão e à determinação, nunca ao que é vago ou aleatório", e dá como exemplo um poema de Emily Dickinson:

A sepal, petal, and a thorn

Upon a common summer's morn -

A flask of Dew - a Bee or two -

A Breeze - a caper in the trees -

And I'm a Rose!

Mestre em Letras pela UFPE.

A sépala - a pétala - o espinho - / Numa manhã qualquer de estio - / O orvalho - uma ou duas abelhas - / No galho - a brisa em viravolta - / E eisme uma Rosa! Os poemas de Emily Dickinson reproduzidos neste texto foram extraidos da compilação de sua obra completa editada por Franklin (1998). Valho-me aqui das minhas próprias traduções "não- 
Estes versos conteriam "um despojamento de linguagem por meio do qual os significados são canalizados por um tecido verbal quase imponderável", nas palavras de Calvino (1990, p. 28), para quem essa autora pode fornecer inúmeros exemplos da "rarefeita consistência" que seria uma das qualidades essenciais da leveza como expressão literária, ligada à sutileza e à sugestão verbal da linguagem (em oposição à noção de peso ou solidez, que privilegiaria a espessura das coisas, dos corpos e das sensações). É interessante associar a essa leveza perceptível na poesia de Emily Dickinson, além das noções de rapidez ("excitação das idéias simultâneas") e exatidão ("uma ciência do único e do irrepetível"), desenvolvidas por Calvino, a idéia de brevidade como ideal estilístico de que fala Curtius (1996, p. 596), citando Horácio: "Precisa-se de brevidade para que a frase seja fluente e não se torne pesada com palavras que irritam os ouvidos". $\dot{A}$ exceção de certas passagens mais obscuras e ambíguas, essa idéia de leveza casa bem com a poesia de Emily Dickinson. Vale notar que as notórias dificuldades de leitura da maioria de seus poemas não a impediram de se tornar uma poeta apreciada por jovens e crianças nos Estados Unidos, onde existem várias coletâneas destinadas ao público infantil. Versos como estes que encantaram Calvino agradam a todos por sua simplicidade e cadência rítmica (sem falar no leve senso de humor implícito em sua conclusão). O poema é um dos que se pode supor sejam perfeitamente compreensíveis por uma criança de língua inglesa: a única dificuldade seriam talvez as palavras sepal e morn, no primeiro verso, que no entanto contribuem, logo de início, para caracterizar o gênero discursivo como sendo uma "adivinhação" (riddle). É claro que a percepção poética de uma criança não the permitiria passar de uma leitura apenas superficial do poema: ela notaria talvez as rimas internas e quem sabe se encantaria com o verso final, espécie de solução para o enigma que se apresenta nos versos anteriores. Emily Dickinson tem vários desses riddles, fórmulas tomadas das cantigas de roda, que não nomeiam o objeto da enunciação. Esses poemas não estão, salvo raras exceções, entre a sua produção mais significativa, em que se situam os versos de especulação metafísica e introspecção irônica que a tornaram

literais" dos poemas, ainda inéditas, que tentam evitar a "normalização" ou "explicação" da dicção da autora. 
conhecida e apreciada, mas não são tão ingênuos como possam parecer à primeira vista. Até neles se pode captar algo de inesperado, como é o caso deste pequeno poema. Nos quatro primeiros versos, metricamente iguais, é uma voz despersonalizada que se ocupa da enumeração dos atributos de um objeto qualquer, não nomeado ( $A$ sepal, petal, and a thorn), da descrição do contexto em que ele estaria situado (Upon a common summer's morn) e da informação sobre outros elementos e situações que compõem o seu "estar-no-mundo" ( $A$ flask of Dew - a Bee or two - / A Breeze - a caper in the trees -). No último verso (que poderia formar, na realidade, uma estrofe distinta), mais curto que os demais, uma outra voz irrompe inesperadamente (And I'm a Rose!). Esta fragmentação do eu lírico, esta aparição de uma voz diferente, às vezes clara (como neste caso), às vezes disfarçada, instaura a polifonia (aqui de modo simples e direto) no texto poético. ${ }^{2}$

Essa "voz diferente" tem, a meu ver, uma origem identificável através do conceito barthesiano de "biografema". Emily Dickinson viveu e escreveu à margem dos círculos literários de sua época, autoexilada em sua própria casa e sem ter publicado em vida os seus

2 A despeito do próprio idealizador da concepção dialógica da linguagem e da polifonia discursiva, Bakhtin $(1998$, p. 88$)$ afirma que "em todos os seus caminhos até o objeto, em todas as direções, o discurso se encontra com o discurso de outrem e não pode deixar de participar, com ele, de uma interação viva e tensa", mas é o próprio Bakhtin (p. 93) que nega ao discurso poético a essência mesma desse princípio: "O estilo poético é convencionalmente privado de qualquer interação com o discurso alheio, de qualquer 'olhar' para o discurso alheio". E mais: a linguagem poética é "única" e "monologicamente fechada" [grifo meu]. Não cabe aqui discutir essa contradição da teoria bakhtiniana, que manifestamente privilegia o discurso romanesco e relega a poesia a segundo plano, mas registro en passant a minha opinião. De fato, se o dialogismo é condição sine qua non da interação humana, não há lugar na linguagem para nenhuma forma de "monologismo". Fora do dialogismo não há linguagem humana - este o princípio em que se funda a teoria bakhtiniana: não pode haver nenhum tipo de enunciação "monológica", na fala ou na escrita, no romance ou na poesia. Poder-se-ia falar, talvez, em algo como "homofonia" em oposição a polifonia, entendido que polifonia é um conceito distinto de dialogismo, lingüisticamente não-essencial e extrínseco ao ato de enunciação. 
poemas, cônscia de sua condição de poeta na mais alta acepção da palavra e não de simples "poetisa". Sob certos aspectos, pode ser considerada hoje em dia uma autora contemporânea, uma vez que apenas cerca de um terço de sua obra havia chegado ao público (assim mesmo através de desastradas edições) antes da segunda metade do séc. XX, quando Johnson (1955) fez a compilação completa dos seus poemas. A escrita de Emily Dickinson, alheia às vozes melífluas e previsíveis da época, ficou impregnada de certa "estrangeirização", a qual teria tido origem na rejeição de seu labor poético, responsável pela eclosão de sentimentos de perda, ausência, melancolia, frustração, luto e dor, entre outros. Essa "intrusão" de certos traços, gostos e inflexões pessoais na escrita foi chamada por Barthes (1984, 1999) de biografema. ${ }^{3}$ Uma das características da "estrangeirização biografemática" dickinsoniana é justamente a brevidade, que se opõe ao vezo da amplificação (amplificatio), herança clássica e medieval, segundo Curtius (1996), e da prolixidade própria dos românticos.

Baseado na idéia de brevidade como ideal de expressão literária, proponho-me esboçar um estudo comparativo enfocando três momentos poéticos distintos, do presente histórico da escrita de Emily Dickinson a um gênero inscrito num passado que ela não chegou a conhecer, mas com o qual tem fortes ligações estilísticas e temáticas, e daí a um discurso futuro de que ela não participou mas do qual, indiretamente, foi precursora. Em termos teóricos, este empreendimento comparatista ampara-se no que Pageaux (1998, p. 295) chama de "comparação de leituras binárias ou plurais" na área da poética, por ele especificadas como "temáticas, transversais, transtextuais ou laterais". Tratar-se-ia, para Pageaux, de "estabelecer um tertium comparationis entre os textos" sem comprovada ligação direta e sem uma evidência clara de intertextualização, ou seja, uma

O tema ou tópico de qualquer um dos poemas de Emily Dickinson pode ser, entre outros, o amor ou a morte ou mesmo a fama (que para ela era uma "posse ablativa"), mas o traço biografemático subjacente em todos os seus textos é a voz de um eu poético alienado, perdido em meio à incompletude enunciativa de uma escrita estrangeirizada. Desenvolvo esses temas em dois outros trabalhos, ainda inéditos, sobre a aplicação da teoria biografemática à crítica literária e sobre alguns aspectos da gramática poética da estrangeirização dickinsoniana. 
"intersecção de conjuntos que têm a sua especificidade individual". Sem tentar explicar biografematicamente a presença de Emily Dickinson nesse entrelugar atemporal em que seu discurso poético se supõe e se projeta, limito-me a apontar certas semelhanças entre a sua obra e dois momentos distintos que a crítica costuma correlacionar no âmbito da literatura universal, quais sejam, a herança lírica oriental, representada principalmente pelo tipo de poesia contemplativa que, no Japão, deu origem à forma fixa conhecida como haicai, e o imagismo, movimento artístico com forte presença na poesia de língua inglesa do início do século passado.

É claro que o comparativismo tem perspectivas bem mais vastas que um ingênuo confronto entre textos "parecidos". Lidando com conceitos amplos e tradicionais como influência, imitação e originalidade, além de valorizar a intertextualidade, a recepção e a teoria da tradução, a literatura comparada "situa-se entre as disciplinas difíceis de serem delimitadas", na opinião de Nitrini (2000, p. 117), que vê nessas "fronteiras nebulosas" um dos fatores das crises cíclicas por que ela passa, inclusive nos dias atuais, com a inclusão dos estudos culturais em sua área de atuação interdisciplinar, abrindo espaço para todas as formas de expressão cultural, tais como o cinema, o videoclip, o romance popular, a literatura infantil, o rock e, entre nós, as novelas de televisão, o cordel e o mangue beat, entre muitas outras. É claro também que não pretendo afirmar - e aqui já tomo a trilha do passado, no primeiro percurso deste estudo - que a totalidade da obra de Emily Dickinson se presta a comparações com a poética oriental. Também não avento nem de longe a possibilidade de constatação de relações intertextuais, forçosamente baseadas na absorção e transformação de outro(s) texto(s), uma vez que Emily Dickinson não teve, ao que se sabe, contato direto ou indireto com a literatura oriental. As semelhanças detectáveis entre a poesia de Emily Dickinson e alguns dos poetas orientais (falo dos haicaístas japoneses), que a antecederam em centenas de anos, não é circunscrita a recursos estilísticos e formais, mas se evidenciam, em sua maior parte, na tematização da natureza, em especial seu green people (árvores e plantas) e sua important population (insetos), como ela os denominou, e (com certas ressalvas) em algumas referências de cunho religioso e filosófico. Poderiam ser tachadas de semelhanças circunstanciais, talvez achados fortuitos, mas nem por isso, a meu ver, 
deixariam de ser pertinentes, até porque são até mais suscetíveis de comparação do que a relação (equiparação) que alguns críticos atuais tentam fazer entre a poesia dickinsoniana e uma suposta "poesia feminina sentimental" de sua época.

Miner (1996, passim) afirma que é preciso "estabelecer uma base para comparação entre coisas que possuem elementos em comum, e num grau de semelhança superior a meras parecenças ou analogias", e acrescenta que o problema "está em saber quais elementos constituem, ou que procedimento garante suficiente comparabilidade" [grifo do autor]. Referindo-se à poética oriental, Miner diz que os chineses, por um lado, gostam de comparar seus poetas Li Bo e Du Fu, e os japoneses, por outro, Matsuo Bashō e Yosa Buson, os quais, em cada caso, "são similares o bastante para serem comparados, embora pareçam muito diferentes um do outro". Já quando se faz uma comparação entre a poesia chinesa e a japonesa, "os chineses agora se tornam muito parecidos entre si, mas diferentes dos japoneses, os quais, por sua vez, também se parecem bastante uns com os outros". Se ampliássemos essa escala, ainda segundo Miner, com a introdução de John Donne e Ben Johnson ou de Vitor Hugo e Charles Baudelaire, por exemplo, nos surpreenderíamos "com as semelhanças entre os poetas da China e do Japão, por um lado, o mesmo acontecendo com os poetas ocidentais, por outro". De tudo isso se deduz que há alguns fatores culturais, difíceis de ser mensurados, que se interpõem no jogo da comparação literária. "Estas considerações são rudimentares", acrescenta o autor, "mas a arte da comparação $[\ldots]$ tem um longo caminho a percorrer, antes que cânones claros nos sejam apresentados". Preocupado em estabelecer critérios de comparação entre as poéticas ocidental e oriental, Miner diz em seguida que, no caso da poética chinesa (da qual, em muitos aspectos, deriva a japonesa), seus elementos constitutivos são "a cena, a natureza, o mundo observável" (jing), seguidos de uma "resposta humana afetiva" (qing), em contraposição à metaforização centrada no uso das palavras que é a característica essencial de nossa literatura. Em meio a alguns textos clássicos da lírica chinesa e japonesa, Miner situa um poema de Emily Dickinson cuja estrofe inicial, em sua opinião, dá uma idéia desse equilíbrio entre jing e qing que permeia a obra dickinsoniana: 
There's a certain Slant of light,

Winter Afternoons -

That oppresses, like the Heft

Of Cathedral Tunes - ${ }^{4}$

A opressão, que é o qing, seria a resposta ao jing, a mistura de luz oblíqua e som pesado das tardes hibernais de Amherst, terra natal de Emily Dickinson.

Os pontos de contato que ressaltam à primeira vista entre Emily Dickinson e a poesia japonesa (que é a que interessa aqui neste momento) são a leveza, rapidez e exatidão de que fala Calvino, consubstanciadas na brevidade formal apregoada por Curtius. Mais de um terço de seus poemas tem no máximo duas estrofes com oito versos curtos de oito ou seis sílabas cada um, contrastando com a prática dos poetas de sua época de extravasar a inspiração em extensos e prolixos poemas: basta dizer que Poe (1996, p. 793) achava o seu poema "The Raven", com dezoito estrofes de seis versos longos e exatas 1.088 palavras, uma "peça curta", ideal para ser apreciada numa "rápida leitura". Numa amostragem entre cinqüenta típicos poemas de quatro e oito versos de Emily Dickinson, comprovei uma média de vinte e duas palavras por poema; no conjunto de sua obra, esse número não chega a sessenta. A forma poética mais comum no Japão durante séculos foi a tanka, duas estrofes de três e dois versos com um total de trinta e um sons (equivalentes, em termos de versificação, à nossa sílaba métrica). O hokku, um simples terceto de dezessete sons, que antes compunha a primeira estrofe da tanka, foi elevado à condição de forma poética fixa por Bashō, que viveu no séc. XVII e ainda hoje é considerado o maior poeta japonês. É digno de nota que a tendência em direção à abreviação, ocorrida através dos séculos com a poesia japonesa, também se verificou com Emily Dickinson, que no decorrer de sua vida foi aos poucos encurtando ("haicaizando") os poemas, até quase fixar-se nos textos mais curtos que iriam caracterizar o seu estilo.

4 A luz tem certa Obliqüidade / Nas Tardes hibernais / Que oprime tanto quanto o Peso / Dos Sons de Catedrais - 
Mas essa aproximação de ordem genérica não justificaria, por si só, esta análise comparativa. Há detalhes bem mais significativos, como por exemplo a não-intitulação dos poemas, modo sutil de realçar a sua transitividade (outra das características identificadas com o conceito de leveza), e a predisposição a não considerá-los uma obra acabada, mas um texto provisório: para Bashō e seus contemporâneos, o haicai estava sempre sujeito a emendas e alterações, por parte até de outros poetas, enquanto, no caso de Emily Dickinson, os poemas ganhavam novos contornos sempre que ela os copiava em seus cadernos ou os enviava a amigos. Ela, em última análise, "escolheu não escolher" entre possíveis versões, como sugere Cameron (1992). ${ }^{5}$ Por outro lado, a ausência de rimas no haicai poderia ser equiparada ao desprezo de Emily Dickinson pela rima perfeita: nunca até então nenhum poeta de língua inglesa havia ousado desafiar, como ela o fez, os padrões estabelecidos para o uso da rima, a ponto de quebrar a tirania desse recurso poético e contribuir para o seu desprestígio entre os poetas modernos.

A poesia japonesa, e em especial o haicai, busca a expressão de uma percepção momentânea, baseada na observação da natureza, e não a obtenção de um efeito calculado. De acordo com Blyth (1941, p. 71), "é possível distinguir quatro tipos de expressão poética: (a) o objeto tratado objetivamente; (b) o objeto tratado subjetivamente; (c) o sujeito tratado objetivamente; $\mathrm{e}$ (d) o sujeito tratado subjetivamente" (o sujeito, no caso é o poeta, e o objeto, o poema). As opções (a) e (c) são próprias da atitude zen e, por extensão, da poética japonesa, afirma o autor. Isto implica na consciente busca da supressão de sentimentos e emoções e do afastamento do poeta (do haicaísta) em relação ao objeto de seu discurso. O objetivo do haicaísta não é escrever "belos versos", inserir purple patches e floreios em seu discurso, voltado para a observação das coisas simples e dos eventos

5 Além das variações textuais de um mesmo poema, Cameron (1992, p. 160) examina a questão da "proximidade" ou reiteração intertextual de um poema em relação a outro: "We find ourselves asking", diz ela, "whether the variants to poems and the poems which work like variants of each other suggest that something is being chosen or that choice is being declined". 
triviais - e eis aqui algumas outras aproximações entre a haicaística e a poética dickinsoniana.

A natureza está no centro das atenções dessa poesia que é essencialmente objetiva mas que não perde a sua aura de contemplação mística. Os animais de toda espécie (e entre eles os insetos), as plantas, as flores e até as pedras compõem o universo poético do haicai. Há poemas e mais poemas sobre baratas e lesmas, sobre seixos e galhos, sobre uma simples formiga ou uma folha morta. Há sempre uma palavra ou expressão, o kigo, que faz referência, direta ou indireta, a um fenômeno natural (o pôr-do-sol e a lua nova, por exemplo) ou a uma das estações do ano, para acentuar o aqui-e-agora do poema e reforçar a idéia de um mundo em perpétua mutação. A natureza exerce um grande fascínio também sobre Emily Dickinson, e é com certeza um dos temas mais recorrentes em sua obra. Mais de um terço de seus poemas abordam diretamente a natureza e suas manifestações. Ela ama os animais, especialmente as pequenas criaturas, como as abelhas e borboletas e também as aranhas, os grilos, as moscas e outros insetos, e até os morcegos têm lugar em sua poesia, junto com os pássaros de todo tipo. Sem ter tido, ao que parece, qualquer contato com a poesia de Emily Dickinson, Suzuki $(1959$, p. 231) se pergunta, voltando o olhar para esses e outros animais "rejeitados": "Será que a mente ocidental foi algum dia tocada poeticamente por criaturas tão insignificantes?" Pois essa aproximação com os seres mais humildes é um tema freqüiente em Emily Dickinson, uma nuança a mais em sua estrangeirização biografemática: sem falar novamente em abelhas e borboletas, que povoam seus poemas, ela também é tocada, por exemplo, por criaturas como uma lagarta: How soft a Caterpillar steps - [Como a Lagarta

- Ao identificar "a mais notável característica" da cultura de seu país, Suzuki (1959, p. 233) ressalta o mesmo tipo de amor pela natureza que a própria Emily Dickinson nutria (ela que cultivava flores das mais diversas espécies em seu jardim): "Perhaps one most egregiously Japanese characteristic is to take notice of the small things of nature and tenderly take care of them. Instead of talking about great ideals or highly abstract thoughts, they cultivate chrysanthemums or morning-glories, and when the season comes they delight to see them bloom beautifully as they planned". 
anda com graça -]; um rato: Papa above! Regard a Mouse / O'erpowered by the Cat! [Papai do Céu! Olha o Ratinho / Que é subjugado pelo Gato!]; uma rã: The long sigh of the Frog / Upon a Summer's Day [A Rã suspira fundo / Num dia de Verão]; e até pelas coisas inanimadas, como a relva: The Grass so little has to do - I A Sphere of simple Green - [A relva faz tão poucas coisas / Um Mundo só de Verde -] e as pedras: How happy is the little Stone / That rambles in the Road alone [Como é feliz uma Pedrinha / Que rola só pelo Caminho], sem falar das plantas e das folhas. Esses poucos exemplos são suficientes para evidenciar que a atitude "nãoocidentalista" de Emily Dickinson é um forte ponto de contato entre a sua poesia e a poética do haicai. Restaria acrescentar o seu profundo interesse pela força destrutiva dos fenômenos naturais, presença constante em suas imagens e metáforas, como o vento, a neve, a chuva, o fogo, as tempestades e as erupções vulcânicas, as enchentes e as secas. Todas as quatro estações estão presentes em seus poemas, e ela as usa como um haicaísta japonês usa o kigo. But nature is a stranger yet, ela diz,

\section{Nature is what we know - \\ Yet have no Art to say - \\ So impotent our Wisdom is \\ To her Simplicity.}

No entender de Pickard (1967, p. 57), para quem ela "mesclou um genuíno entusiasmo pela beleza aparente da natureza com a consciência de seu mistério e estranhamento", sua visão excedia a dos artistas românticos e cientistas da época, "cuja pretensa intimidade com a natureza traía uma falta de percepção". Aiken (1963, p. 13) observa com propriedade: "Seus poemas sobre a natureza mostram,

7 A Natureza é o que sabemos - / Mas a Arte não diria - / Tão cega é para o que é simples / Nossa Sabedoria.

8 Bem mais direta é a percepção de Lubbers (1970, pp. 203-204): "Das Verhältnis von Mensch und Natur war für Emily Dickinson ein zentrales Thema, denn es stellte sie als Dichterin und Denkerin vor unüberschreitbare Grenzen. Hier Mensch, dort Natur. Und gleichgültig, was der Mensch unternimmt, um die Natur zu fassen - sie entzieht sich seinem Zugriff stets". 
quase sempre de modo ágil e breve, uma peculiar exatidão. [...] Sua autêntica reverência, a reverência que fez dela uma poeta mística do melhor quilate, era reservada à natureza".

A reverência às coisas místicas é outro ponto de aproximação entre a lírica japonesa, toda ela impregnada da filosofia zen, e a poesia de Emily Dickinson. As mesmas palavras de Paz (1990, p. 174), referindo-se à beatitude alcançada por Bashō, "esse sentimento de universal simpatia com tudo o que existe, essa fraternidade na impermanência com homens, animais e plantas, que é o melhor que nos foi legado pelo budismo", podem ser aplicadas a Emily Dickinson, que almeja uma comunhão cósmica entre os seres humanos e todos os outros seres e coisas do universo, chegando a preocupar-se com a salvação (no sentido religioso) daquele ratinho apanhado por um gato. ${ }^{9}$ É possível também assinalar certas semelhanças de uso da linguagem entre Emily Dickinson e o haicai, apesar do abismo que separa o japonês e as línguas ocidentais. $\mathrm{O}$ discurso instigante de Emily Dickinson "desafiou e rompeu as convenções de sua época", de acordo com Byron (2000, p. 71), para quem os seus poemas, cuja cadência "não tem a menor semelhança com os sons fluidos e melífluos com os quais os seus leitores estavam mais familiarizados, são notavelmente diferentes" [da poesia tradicional do Séc. XIX]. A linguagem de Emily Dickinson é ainda hoje, na verdade, uma nova experiência para qualquer leitor e está

9 Paz (1990, p. 173) já havia notado que "há um momento japonês" na poesia de António Machado, mas critica sua tendência à explicação e à reiteração, que elimina a sugestão, "essa parte não express $a$ do poema [...] na qual está realmente a poesia" [grifos do autor]. Essa observação reforça a aproximação entre Emily Dickinson e a estética japonesa: explicar e reiterar são recursos de que ela não se vale normalmente em seus poemas. Outra característica própria do haicai apontada por Paz (1990, p. 174) é a "relação pungente, dolorosa, entre a existência humana e o destino dos animais e plantas", que está presente, por exemplo, em Kobayashi Issa, outro grande haicaísta: "Para o mosquito / Também a noite é longa / E solitária". Essa "fraternidade cósmica na dor" é uma constante em Emily Dickinson: Auto da Fe - and Judgment - / Are nothing to the Bee - / His separation from His Rose - / To Him - sums Misery - [O Auto da Fé e o Dia do Juízo / Nada são para a abelha - / É a separação da sua rosa / Que na miséria a deixa -]. 
próxima do uso lingüístico observado no haicai (a julgar pelas traduções de que tenho conhecimento, dada a minha ignorância do idioma japonês), explicando-se assim, pelo menos em parte, essa impressão de algo estranho aos padrões da lógica de herança helênica. Byron viu nela quatro características principais, todas encontráveis na poética japonesa tradicional: alta compactação da linguagem, contextualização inusitada, aproximação com a língua falada e uso de imagens concretas e visuais. Esta última, que permite a expressão de idéias abstratas através de imagens "concretas", perceptíveis de imediato, indica, na visão de Byron, um alto grau de qualidade na poesia lírica. E é esta última característica, mais que todas as outras, que dá maior nitidez à aproximação entre o vetusto haicai e os poemas de Emily Dickinson, bem como entre estes e - entrando agora neste "túnel do tempo" em direção ao futuro - as produções de poetas que se diziam "imagistas".

O imagismo foi um movimento iniciado por poetas de língua inglesa, liderados por Ezra Pound, nas primeiras décadas do séc. XX. Pound, que se propunha, com seu instigante preceito Make it new!, dar um novo impulso à poesia, havia mergulhado no estudo da poética oriental e se empenhou na tradução e divulgação de poetas chineses e japoneses, pondo em voga, entre os adeptos do modernismo que então surgia na Europa, certas técnicas "orientalistas" baseadas na valorização dos aspectos visuais do texto poético. ${ }^{10} \mathrm{O}$ poema imagista é caracterizado por uma linguagem concreta e exata, despida de generalizações ou digressões, que visa reproduzir a percepção direta de uma cena ou de um objeto. Como bem resume Azerêdo (2000, p.

10 Cabe aduzir, como o faz Hughes (1973, p. 3), que o imagismo não surgiu de alguma súbita idéia genial de Pound: "We are faced by the fact that nothing is as new as it appears at first to be. Everything has a string of precedents. Imagism, like nearly all movements in literature, was a reaction against the poetry of the immediate past, at least of the immediate past in England and America. (...) Its sources of influence were, chronologically, of two sorts: ancient and modern". As literaturas antigas que serviram de fonte de inspiração para o imagismo foram, de acordo com o mesmo autor, além da grega e da latina, a hebraica, a chinesa e a japonesa. A moderna influência teria vindo da França, através do simbolismo. 
25), "na poética imagística, a imagem não é considerada apenas uma parte do poema, mas constitui o próprio poema".

A questão da forma, que no haicai, por se tratar de um poema curto com medidas fixas, é inflexível, não é determinante no imagismo, em vista do predomínio do verso livre, que já então fazia escola. Mas o haicai era, para os imagistas, o modelo ideal de perfeição e pureza de linguagem. O mais conhecido poema imagístico de Pound, e talvez de todo o movimento, "In a Station of the Metro", é considerado um haicai "moderno", por sua estrutura rítmica e métrica, pela referência dêitica ao aqui-e-agora, pela representação de elementos da natureza e sobretudo pela concretude de sua linguagem, que tenta capturar a imagem fugidia de um instante irrepetível:

The apparition of these faces in the crowd:

Petals on a wet, black bough. ${ }^{11}$

Esses poemas curtos, no entanto, não são peças obrigatórias na obra dos imagistas, que se valiam com freqüência de longas descrições e intertextualizações e da superposição de imagens e metáforas, com a introdução esporádica de "momentos haicaísticos" em seus versos. A influência do haicai, em termos de inovação conceptual, foi crucial para Pound e os imagistas, como o foi, posteriormente, para os poetas da geração beat, os quais, no entanto, se prenderam (e se perderam) em certos aspectos não-essenciais do haicai, atraídos pelos preceitos filosóficos do zen-budismo. Mas não seria de esperar que a rigidez dessa forma poética servisse a todos os propósitos da poesia modernista, cujas preocupações estéticas transcendem a contemplação e o ascetismo ainda hoje intrinsecamente inerentes a esse gênero poético oriental. Comentando um poema de William Carlos Williams que é outra das mais famosas obras do imagismo, Yasuda (2000) toca num ponto crítico ao comparar a concisão imagística do haicai e a tendência à verbalização e à racionalização de nossos poetas:

11 Reproduzo a tradução de Augusto de Campos ("Numa Estação de Metrô"), usada por Azerêdo para ilustrar alguns de seus pontos de vista, na qual é introduzido um recurso visual inexistente no texto de Pound, com espaçamentos maiores do que o usual entre algumas palavras: A visão dessas faces dentre a turba: / Pétalas num ramo úmido, escuro. 


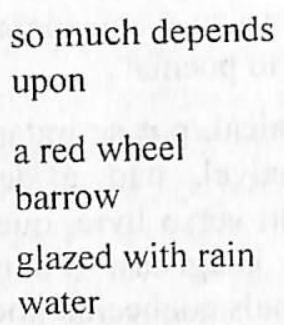

$$
\begin{aligned}
& \text { beside the white } \\
& \text { chickens }{ }^{12}
\end{aligned}
$$

Este poema é mais longo que o de Pound e tem menos "sabor" de haicai, em vista da explícita asserção contida nos dois primeiros versos. "O prazer que um haicai proporciona é intuitivo e imediato, e não se apóia no raciocínio lógico", diz Yasuda (2000, p. 6-7). É claro que, sob o ângulo filosófico-racional, a poesia de Emily Dickinson - para usar a analogia traçada por Miner - também se prestaria, não sei se bem ou mal, à comparação com a de William Carlos Williams ou, em última análise, com a de qualquer outro poeta não-oriental, face à "aristotelização" generalizada do pensamento ocidental. A imagem poética, num haicai como num poema imagista, é expressa através da apresentação dos objetos concretos que a compõem. É evidente, porém, que essa apresentação passa pela percepção que o poeta tem do mundo, como se depreende das relações de equivalências paradigmáticas entre rostos e pétalas no poema de Pound.

Para melhor situar esta comparação entre a poesia de Emily Dickinson e a dos poetas anglo-americanos que "descobriram" e imitaram a poética oriental, volto a atenção para um de seus poemas de cunho imagístico:
A Route of Evanescence
With a revolving Wheel -
A Resonance of Emerald -
A Rush of Cochineal -
And every Blossom on the Bush

12 Reproduzo a tradução de Paulo Vizioli (1983, p. 117): e tanto depende / daquele // carrinho de mão / vermelho // na chuva luzindo / lustroso // junto dos frangos / brancos. 
Adjusts its tumbled Head -

The mail from Tunis, probably,

An easy Morning's Ride - ${ }^{13}$

Anderson (1960, p. 114) detecta de imediato que o poema "se aproxima de um haicai japonês [...] ao reduzir um fenômeno natural a uma imagem mental". E se pergunta de que outra forma seria possível a um artista representar, através da linguagem, um beija-flor, "exemplo extremo, na natureza, de uma forma indefinível". Falando sobre a força sinestésica desses versos, Anderson observa: "O efeito visual é uma inversão do efeito fotográfico de múltiplas e rápidas exposições de um objeto em movimento sobre uma chapa. Os versos iniciais registram não a aparição simultânea, mas o simultâneo esvaecer do pássaro a cada momento". ${ }^{14}$

Estudando a presença de elementos visuais na poesia de Dickinson, afirma Farr, depois de observar que neste poema every word $[i s]$ a picture:

Dickinson deixa bem clara sua imaginação visual em centenas de poemas. Muitos deles a fazem parecer uma pintora que estuda primeiro o que vê e então executa 0 cenário. [...] Embora fixe o olhar, como o faria um pintor, num quadro estático [...], ela prefere descrever a natureza em movimento ou mudança. Quando fala do nascer do sol [...], ela costuma mostrar como o evento progride: I'll tell you how the Sun rose - / A Ribbon at a time [O Sol nasceu como lhe digo - / Uma Réstia por vez -] (Farr, 1999, p. 68).

${ }^{13}$ Uma Rota de Evanescência / Em inquieta Propulsão - / A ressonância da Esmeralda - / A explosão do Carmim - / E cada Flor pelo Caminho / Ergue-se em sua Direção - / Novas que vêm talvez de Túnis / Voando à toa assim -

$14 \mathrm{Na}$ verdade, os comentários do autor referem-se especificamente aos primeiros quatro versos do poema: ele comentava o uso da palavra evanescence (evanescência). Falando sobre o efeito de sinestesia desses versos, Anderson (1960, p. 114) observa: "The visual effect is the converse of the photographic one of multiple rapid exposures of a moving object on a single plate. Her first line records not the simultaneous presence but the simultaneous vanishing of the bird at every point". 
"O impacto das imagens visuais de alguns dos melhores poemas de Emily Dickinson tem relação com o impacto das imagens visuais de alguns de nossos modernos experimentos no campo da cinemática", diz Dyer (1969, p. 123) ao comentar este poema. ${ }^{15}$ Esse "claro enigma", essa incompletude intrínseca de um discurso poético constituído de elementos referenciais, supostamente concretos e visualizáveis, é uma das características essenciais do haicai, da poesia de Emily Dickinson e, por extensão, do imagismo, os quais, apesar de visarem à exposição mais objetiva possível de uma cena, não prescindem da participação do leitor para sua apreensão. Bem que o poeta, quem diz é a própria Emily Dickinson, Distills amazing sense / From ordinary Meanings [Extrai um senso inusitado / Dos Sentidos comuns] - mas esse mesmo senso (sentido) tem de ser recuperado (recriado) pelo leitor.

Mas eis que comprometo a brevidade, que é (ou deveria ser) uma exigência de qualquer ensaio crítico. Para concluir, eis outro exemplo da força imagística de Emily Dickinson: um pequenino poema que qualquer imagista, de Pound aos poundianos e aos neopoundianos, gostaria de ter feito:
An Everywhere of Silver
With Ropes of Sand
To keep it from effacing
The Track called Land. ${ }^{16}$

15 As observações da autora parecem ser, na verdade, uma apropriação quase literal dos comentários de Anderson sobre o mesmo poema: "It has been noted that", diz Dyer (1969, p. 123), modalizando casualmente o seu discurso, "the total effect of the visual images in this poem is actually related to the photographic process in general. Actually Dickinson's inspired use of visual images represents an inversion of the photographic process: instead of the simultaneous exposure of a moving object, she details the simultaneous vanishing of the object at every point'.

Um não-acabar de Prata / De Areia se amarra / Para evitar que destrua / A Trilha de Terra. O uso de everywhere como substantivo é uma típica inovação dickinsoniana. O poema é, na verdade, um riddle, e neste caso eu poderia ter feito uma tradução em "prosa vil", mais exata, mas restaria o problema: como traduzir esse everywhere - um "todo-lugar"? 
Este poema contém uma imagem visual quase impensável, não só em termos de poesia, mas de realidade observável, para a época em que viveu Emily Dickinson. Este poema é um não-poema, no sentido estrito de um texto escritural: é só imagem visual: as palavras, em estado bruto, situam-se num único espaço de memória, num só campo de visão: o poema diz, mas não revela o que diz e sim o que mostra. É só imagem. Uma imagem sui generis, esse poema: uma imagem do oceano e dos mares em volta da terra, que parece ter sido captada não de terra nem de um navio (ou de um balão), mas de algum lugar do espaço sideral, a bordo de uma nave espacial.

Estranho, extremo exemplo de estrangeirização.

En art, il s'agit d'être intéressant.

Valho-me de Borges (2000, p. 105), cultor de haicais nas horas vagas, para justificar, se não a ligeireza destas investigações comparatísticas, pelo menos a lógica atemporal que me levou à temerária inclusão de Emily Dickinson nesses entremundos haicaísticos e imagísticos - a aproximação da poética da brevidade e da leveza dickinsoniana com outras percepções estéticas distantes no tempo e no espaço: "Somos mortais porque vivemos no passado e no futuro - porque lembramos um tempo em que não existíamos e antevemos um tempo em que estaremos mortos".

\section{Referências}

AIKEN, Conrad. Emily Dickinson. In: Emily Dickinson: collection of critical essays. Richard B. Sewall (ed.). New Jersey, EUA: PrenticeHall, 1963.

ANDERSON, Charles R. Emily Dickinson's poetry: stairway of surprise. Nova York: Holt, Rinehart \& Winston, 1960.

AZERÊDO, Genilda. Letra Viva, n. 2, 2000, p. 23-30.

BAKHTIN, Mikhail. Questões de literatura e de estética. Trad. Aurora Fornoni Bernadini e outros. São Paulo: Hucitec, 1998.

BARTHES, Roland. A câmara clara. Trad. Júlio Castañon Guimarães. Rio de Janeiro: Nova Fronteira, 1984. 
BARTHES, Roland. Sade, Fourier, Loiola. Trad. Maria de Santa Cruz. Lisboa: Edições 70, 1999.

BLYTH, R. H. Zen in English literature. Tóquio: Hokuseido, 1941.

BORGES, Jorge Luis. Esse ofício do verso. Trad. José Marques Macedo. São Paulo: Cia. das Letras, 2000.

BYRON, Glennis. Emily Dickinson: selected poems. Londres: Longman, 2000.

CALVINO, Italo. Seis propostas para o próximo milênio. Trad. Ivo Barroso. São Paulo: Cia. das Letras, 1990.

CAMERON, Sharon. Choosing not choosing. Chicago, EUA: Univ. of Chicago, 1992.

CURTIUS, Ernst Robert. Literatura européia e Idade Média latina. Trad. Teodoro Cabral e Paulo Rónai. São Paulo: Hucitec, 1996.

FARR, Judith. Dickinson and the visual arts. In: Gudrun Grabher et al. (eds.). The Emily Dickinson Handbook. Amherst, EUA. Univ. of Massachusetts, 1999.

FRANKLIN, R. W. The poems of Emily Dickinson. Cambridge, EUA: Harvard U. P., 1998.

HUGHES, Glenn. Imagism and the imagists: a study in modern poetry. Nova York: Biblo-Moser, 1973.

JOHNSON, Thomas H. The complete poems of Emily Dickinson. Cambridge, EUA: Harvard U. P., 1955.

LUBBERS, Klaus. Nachwort. In: Gertrud Liepe, Emily Dickinson: Gedichte. Stuttgart: Reclam, 1970.

LUCAS, Dolores Dyer. Emily Dickinson and riddle. DeKalb, EUA: Northern Illinois Univ., 1969.

MINER, Earl. Poética comparada. Brasília: UnB, 1996.

NITRINI, Sandra. Literatura comparada. São Paulo: EDUSP, 2000.

PAGEAUX, Daniel-Henri. Littérature comparée et comparaisons. Revue de Littérature Comparée, n. 3, 1998, p. 285-307.

PAZ, Octavio. Signos em rotação. Trad. Sebastião Uchoa Leite. São Paulo: Perspectiva, 1990. 
PICKARD, John B. Emily Dickinson: an introduction and interpretation. Nova York: Holt, Rinehart \& Winston, 1967.

POE, Edgar Allan. The philosophy of composition. In: George McMichael (ed.). Anthology of American Literature. New Jersey, EUA: Prentice Hall, 1996.

SUZUKI, D. T. Zen and Japanese culture. Princeton, EUA: Princeton U. P., 1959.

VIZIOLI, Paulo. A tradução de poesia em língua inglesa: problemas e sugestões. Tradução \& Comunicação, São Paulo, n. 2, 1983, p. 109128.

YASUDA, Kenneth. The Japanese haiku. Boston, EUA: Tuttle, 2000. 